\title{
Sistem Interchangeable pada Sepatu Wanita
}

\author{
Saffira Ghiftama dan Primaditya Hakim \\ Departemen Desain Produk Industri, Fakultas Arsitektur Desain dan Perencanaan, \\ Institut Teknologi Sepuluh Nopember (ITS) \\ e-mail: ghiftamasaffira@gmail.com
}

\begin{abstract}
Abstrak-Produk fesyen yang sering wanita gunakan adalah produk sepatu hak. Namun penggunaan dalam kurun waktu tertentu memberikan dampak yang negatif pada bagian kaki dan tubuh. Untuk mensiasati dan mengurangi dampak negatif tersebut, maka didesainlah sepatu wanita dengan hak lepaspasang. Sepatu ini memiliki sistem sambungan yang telah terintegrasi antar komponen utama dengan komponen lainnya. Hal tersebut didukung dengan komponen insol yang fleksibel. Metode yang dilakukan adalah studi literatur dan observasi. Adapun output dari perancangan yang dilakukan adalah desain sepatu wanita dengan hak yang dapat dilepas pasang.
\end{abstract}

Kata Kunci: ergonomi, sepatu wanita, sistem interchangeability

Abstract-Fashion product that women often use are heels shoes. But the use in a certain period of time has a negative impact on the legs and body. To anticipate and reduce these negative impacts, women's shoes with interchangeable heels are designed. This shoe has a connection system that has been integrated between the main components with other components. This is supported by a flexible insol component. The method used is literature study and observation. The output of the design carried out is the design of women's shoes with removable heels.

Keywords: ergonomic, interchangeablility system, women shoes

\section{PENDAHULUAN}

Seiring dengan kemajuan zaman, peran wanita di dalam dunia karier semakin meningkat. Berdasarkan survei yang dilakukan oleh Badan Pusat Statistik Indonesia, dari 17 sektor pekerjaan, pekerja wanita mendominasi pada tiga sektor dengan persentase lebih dari 60 persen. Selain itu, kaum wanita memiliki nilai upah yang lebih tingg idari pria pada lima sektor [1].

Selain harus bekerja secara maksimal dan profesional, seorang wanita juga dituntut untuk berpenampilan menarik. Penampilan tersebut ditunjang dengan menggunakan produk fashion dan salah satunya adalah produk sepatu hak. Namun penggunaan sepatu hak yang melebihi anjuran pemakaian yaitu maksimal 3 jam [2], dapat memberikan dampak negatif pada bagian kaki dan tubuh. Sepatu hak akan mengakibatkan tekanan yang tinggi pada permukaan telapak kaki sehingga akan memicu kram kaki (metatarsalgia). Keadaan tubuh yang tidak seimbang ketika menggunakan sepatu hak dalam periode yang cukup lama dapat menyebabkan otot bagian kaki mengecil dan memendek [3].

Untuk mencegah dan memperbaiki dampak negatif dari pemakaian sepatu hak, maka perlu adanya pengaturan jangka waktu pemakaian sepatu hak. Seringkali masyarakat merasa terbebani ketika harus membawa satu hingga dua pasang sepatu untuk mengganti sepatu hak yang sedang dipakai. Maka dari itu terciptalah ide mengenai perancangan desain sepatu dengan hak lepas-pasang yang juga memperhatikan faktor ergonomi.

\section{A. Rumusan masalah}

Berdasarkan latar belakang, berikut ini adalah beberapa permasalahan yang ada :

1. Ketidakpraktisan dan ketidakefisienan ketika ingin membawa sepatu dengan jenis hak yang berbeda dalam satu hari. Satu sampai dua pasang sepatu hak tentunya tidak cukup ketika di bawa di dalam tas jinjing kerja.

2. Ketidaknyamanan ketika menggunakan sepatu hak dalam kurun waktu 5-8 jam sehari untuk pekerja wanita tidak hanya berdampak buruk pada area kaki, tetapi juga berdampak buruk pada area tulang belakang [ 4 dan 5].

3. Produk sepatu wanita memiliki potensi yang sangat bagus dari segi bisnis, hal ini tentunya mengakibatkan ketatnya persaingan antar produk sejenis sehingga memerlukan inovasi baru untuk mendobrak pasar, salah satunya dari segi desain serta fitur.

\section{B. Batasan masalah}

1. Produk output yang dihasilkan adalah produk sepatu wanita, dengan bagian hak yang dapat diganti dengan ketinggian $2 \mathrm{~cm}, 5 \mathrm{~cm}$, dan $7 \mathrm{~cm}$ dengan berbagai macam varian bentuk.

2. Segmen yang dituju adalah wanita dengan range umur 25-35 tahun.

3. Konsep yang akan digunakan pada sepatu wanita ini adalah Interchangeable.

4. Teknik produksi yang digunakan untuk membentuk bagian hak sepatunya adalah menggunakan teknik Injeksi molding plastik.

Desain Sepatu Wanita Interchangeable

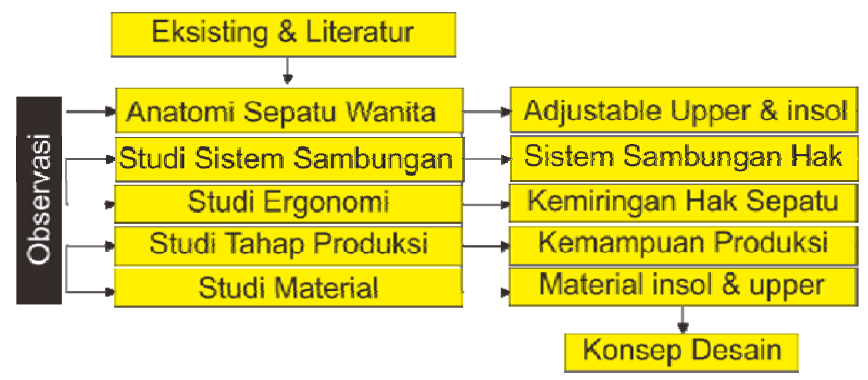

Gambar 1. Alur metode penelitian

\section{Tujuan}

Penelitian ini memiliki tujuan dan manfaat yang menekankan pengembangan fitur dari produk sepatu wanita. Selanjutnya tujuan dapat diuraikan sebagai berikut: 
1. Mengurangi frekuensi waktu ketika wanita menggunakan sepatu hak tinggi, karena dapat dirubah menjadi sepatu hak rendah ketika area kaki merasa sakit dan lelah.

2. Menghasilkan produk sepatu wanita yang sesuai dengan kharakter wanita karier yang memiliki tingkat mobilitas tinggi.

3. Menghasilkan pengembangan produk sepatu wanita yang dapat menunjang kebutuhan wanita karier akan sepatu yang nyaman dan sehat ketika digunakan selama kurang lebih lima sampai delapan jam per hari.

4. Menghasilkan produk sepatu wanita yang dapat bersaing dengan kompetitor di dalam negeri.

\section{METODE PENELITIAN}

\section{A. Metode pengumpulan data}

Alur metode penelitian dengan judul sistem interchangeable sepatu wanita dapat dilihat pada Gambar 1. Metode yang digunakan dalam penelitian ini adalah observasi pada kajian pustaka dan kajian lapangan mengenai produk sepatu hak wanita interchangeable yang telah ada. Kajian pustaka diperoleh dari beberapa literatur yang membahas tentang anatomi sepatu hak wanita, sistem sambungan hak sepatu wanita interchangeable, dan studi ergonomi sepatu hak wanita. Sedangkan kajian lapangan adalah berupa kajian produk sepatu wanita interchangeable yang sudah ada, serta pengamatan pada proses pembuatan sepatu hak wanita. Penelitian ini menggunakan metode dasar kualitatif, dimana proses pengambilan data dianalisis dan diolah untuk mencari hasilnya, hal ini dilakukan dengan data-data:

a. Data primer, berupa data langsung dari hasil pengisian kuisioner dan deep interview.

b. Data sekunder, berupa data yang diperoleh dari studi literatur/ pustaka dan browsing website internet.

\section{B. Studi eksplorasi sistem sambungan hak sepatu}

Studi eksplorasi sistem sambungan hak sepatu ini bertujuan untuk menemukan kemungkinan sambungan hak sepatu yang paling efisien dan mudah penggunaannya.

Sistem sambungan sepatu hak yang dibuat mengacu pada beberapa referensi penelitian yang sebelumnya telah dibuat. Ada beberapa acuan yang menggunakan sistem sambungan sliding dan ada yang menggunakan sistem rotasi.

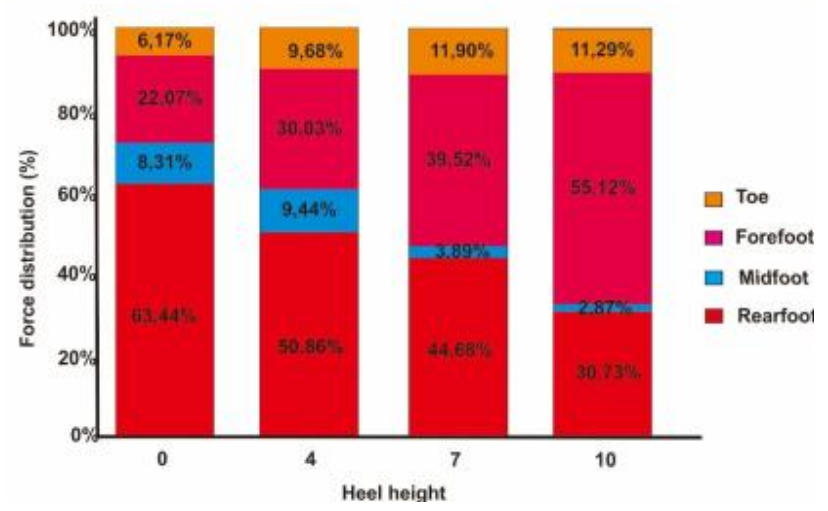

Gambar 2. Persebaran tekanan tubuh pada area kaki
Selain sistem sambungan hak sepatunya, terdapat beberapa hal yang harus diperhatikan yaitu sistem kuncian hak dan kefleksibelan insolnya. Sistem kuncian mengacu pada penelitian yang sebelumnya dengan pengembangan. Kuncian akan mengunci pada keadaan normal, dan akan terlepas ketika tombol ditarik ke arah atas. Dengan posisi tegak lurus dengan permukaan lantai.

Pemasangan engsel serta sudut kemiringannya mengacu pada penelitian sebelumnya yang telah dibuat dengan perubahan pada jenis engselnya. Pada bagian tengah insol pada kedua sepatu tersebut telah dipasang engsel. Hal tersebut dilakukan agar sepatu dapat lebih fleksibel, namun tetap rigid (karena sepatu hak harus memiliki sifat insol yang kaku, kokoh, dan rigid agar dapat menopang berat badan pengguna dengan baik. Berbanding terbalik dengan sepatu olahraga yang mengharuskan keseluruhan insolnya agar fleksibel). Pemasangan engsel ini dimaksudkan agar sepatu dapat menapak pada dataran lantai dengan baik ketika digunakan berjalan. Karena sebelumnya pada prototip pertama tidak dapat menapak pada lantai dengan baik ketika haknya diganti dengan ukuran tinggi hak yang rendah. Pemasangan engsel ini pun dipasang dengan kemiringan 30 derajat dari tulang jempol paling bawah. Pemasangannya ditutup dengan upper agar tidak terlihat aneh dan janggal dari kejauhan.

Berikut ini adalah analisis serta proses beberapa sistem sambungan yang telah dibuat dan telah dicoba sebelumnya. Eksperimen ini dibagi menjadi dua tahap. Eksperimen tahap pertama adalah proses pembuatan mock up pertama, sementara eksperimen tahap kedua adalah proses pembuatan mock up kedua yang merupakan perbaikan dari mock up pertama. Pada eksperimen tahap pertama, alternatif sistem sambungan yang dibuat berjumlah enam alternatif.

Sementara pada eksperimen tahap kedua, alternatif sistem sambungan yang dibuat berjumlah tiga alternatif. Alternatif sistem sambungan kedua merupakan gabungan dari beberapa sistem sambungan yang ada pada eksperimen tahap pertama. Beberapa sistem sambungan menggunakan sistem sliding dan sebagian menggunakan sistem rotasi. Pemilihan sistem sambungan didasarkan atas beberapa faktor yakni faktor kekuatan, keawetan dan ketahanan, kemudahan pembuatan, keringanan dimensi, kepraktisan pengaplikasian sistem kuncian, dan variasi bentuk heels yang dihasilkan.

Tabel 1. Referensi Sudut Kemiringan Sepatu Hak berdasarkan tinggi dan panjang bantalannya

\begin{tabular}{|c|c|c|c|}
\hline No. & $\begin{array}{l}\text { Ketinggian } \\
\text { hak / Heel } \\
\text { height }(\mathrm{H})\end{array}$ & $\begin{array}{c}\text { Panjang } \\
\text { Bantalan } \\
\text { Sepatu Hak / } \\
\text { Heel seat } \\
\text { length (L) }\end{array}$ & $\begin{array}{c}\text { Sudut } \\
\text { Kemiringan } \\
\text { Hak/ Heel } \\
\text { Wedge Angle } \\
(\boldsymbol{\Theta})\end{array}$ \\
\hline \multirow[t]{2}{*}{1} & \multirow[t]{2}{*}{$25 \mathrm{~mm}$} & $45 \mathrm{~mm}$ & 5 \\
\hline & & $67,5 \mathrm{~mm}$ & 4 \\
\hline \multirow[t]{2}{*}{2} & \multirow[t]{2}{*}{$50 \mathrm{~mm}$} & $45 \mathrm{~mm}$ & 8 \\
\hline & & $67,5 \mathrm{~mm}$ & 10 \\
\hline \multirow[t]{2}{*}{3} & \multirow[t]{2}{*}{$75 \mathrm{~mm}$} & $45 \mathrm{~mm}$ & 18 \\
\hline & & $67,5 \mathrm{~mm}$ & 18 \\
\hline
\end{tabular}

\section{Studi teori kelandaian sepatu hak}

Sudut kemiringan hak $(\Theta)$ menentukan tingkat kenyamanan sepatu. Karena berhubungan dengan tinggi hak / heel height 
(H) dan panjang bantalan tumit / heel seat length (L). Jika digambarkan seperti segitiga siku-siku yang dapat dihitung dengan menggunakan rumus trigonometri.

Sudut kemiringan hak ini diperlukan agar tingkat persebaran tekanan tubuh pada area kaki dapat menyebar dengan baik. Karena untuk setiap ketiggian hak yang berbeda, angka persebaran tekanan tubuh juga berbeda. Semakin tinggi hak sepatunya, maka semakin besar tekanan tubuh pada daerah kaki depan (Forefoot). Persebaran tekanan tubuh dibagi menjadi empat daerah pada kaki, yaitu toe, forefoot, midfoot, dan rearfoot (Gambar 2).

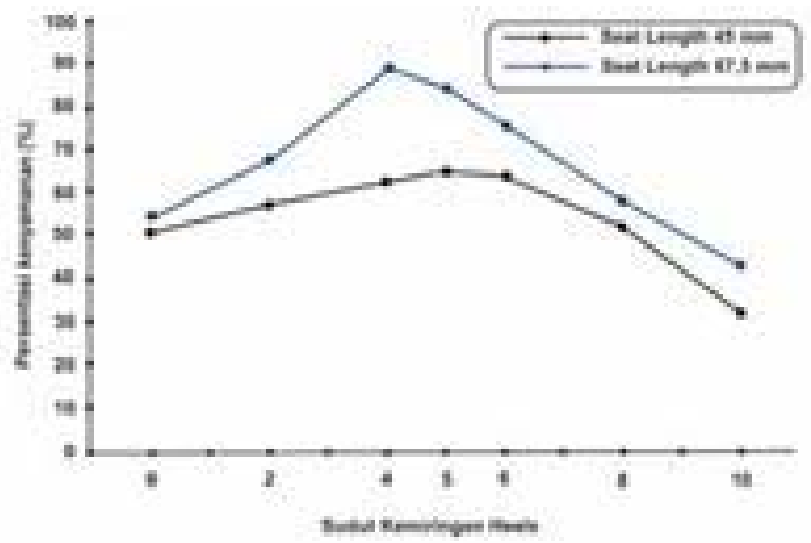

Gambar 3. Hubungan sudut kemiriangan hak ketinggian $25 \mathrm{~mm}$ dengan prosentase tingkat kenyamanannya

Tabel 1 menunjukkan referensi kemiringan hak, dengan ukuran panjang bantalan (L) yang telah ditetapkan oleh dua peneliti sebelumnya yaitu Adrian pada tahun 1991 dengan panjang bantalan $45 \mathrm{~mm}$, dan Witana pada tahun 2009 dengan panjang bantalan $67,5 \mathrm{~mm}$.

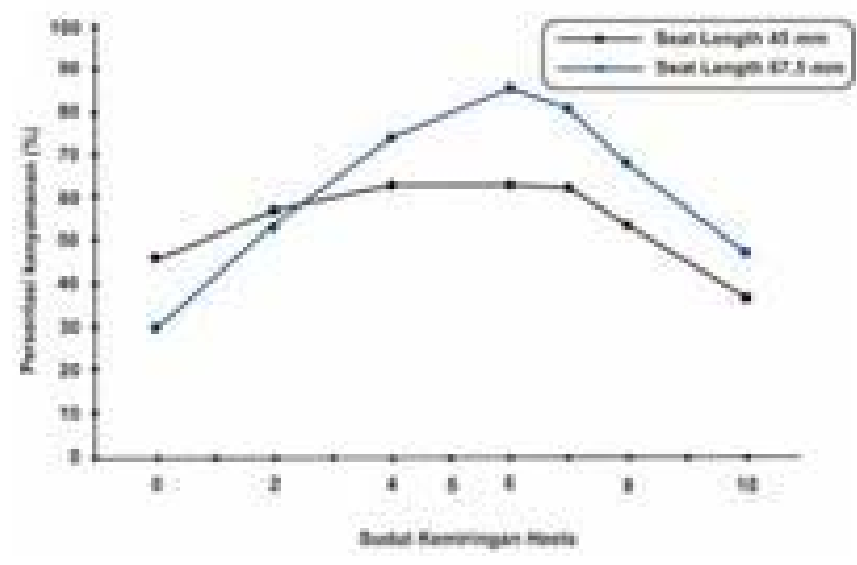

Gambar 4. Hubungan Sudut Kemiriangan hak ketinggian $50 \mathrm{~mm}$ dengan prosentase tingkat kenyamanannya

Dari data tabel tersebut, dapat disimpulkan bahwa, hak dengan ketinggian $25 \mathrm{~mm}$ memiliki tingkat kenyamanan pada kemiringan antara 4-5 derajat. Untuk hak dengan ketinggian $50 \mathrm{~mm}$ memiliki tingkat kenyamanan pada kemiringan 8-10 derajat. Dan untuk hak dengan ketinggian $75 \mathrm{~mm}$ memiliki tingkat kenyamanan pada kemiringan 18 derajat. Berikut ini grafik mengenai persentase normalisasi perasaan yang dirasakan ketika menggunakan tinggi hak 25 $\mathrm{mm}, 50 \mathrm{~mm}$, dan $75 \mathrm{~mm}$ (Gambar-gambar 3,4 dan 5).

\section{Studi material insol dan outsol sepatu}

1. Insol

Insol merupakan sebuah lapisan bahan sebagai perantara antara outsol dengan lining. Insol berfungsi menambah faktor kenyamanan pada kaki karena bahannya yang menyesuaikan dengan jenis sepatu dan kebutuhan penggunanya. Ada beberapa faktor yang mempengaruhi pemilihan bahan insol diantaranya adalah faktor kekuatan/kepadatan, kecocokan tingkat kekakuan/ stiffness bahan, daya serap keringat, dapat menyesuaikan bentuk sepatu, ketahanan abrasi, dan kemudahan memperoleh bahan. Berdasarkan faktor-faktor tersebut bahan insol yang paling tepat digunakan adalah bahan insol texon.

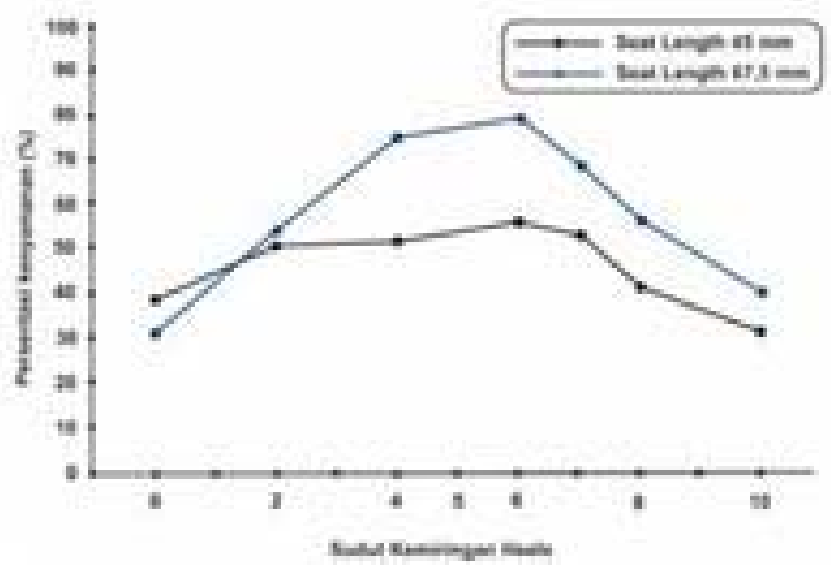

Gambar 5. Hubungan sudut kemiriangan hak ketinggian $75 \mathrm{~mm}$ dengan prosentase tingkat kenyamanannya

\section{Outsol}

Outsol merupakan bagian paling dasar sepatu yang langsung bersentuhan dengan tanah. Hal yang mempengaruhi kriteria outsol adalah daya cengkeramnya (grip), daya tahan terhadap air (abrasi), karena bahannya yang menyesuaikan dengan jenis sepatu dan kebutuhan penggunanya. Ada beberapa faktor yang mempengaruhi pemilihan bahan insol diantaranya adalah faktor kekuatan/kepadatan, kecocokan tingkat kekakuan/ stiffness bahan, daya serap keringat, dapat menyesuaikan bentuk sepatu, ketahanan abrasi, dan kemudahan memperoleh bahan. Berdasarkan faktor-faktor tersebut bahan insol yang paling tepat digunakan adalah bahan

\section{HASIL DAN PEMBAHASAN}

\section{Evaluasi Sistem Sambungan}

Berikut ini adalah analisis serta proses beberapa sistem sambungan yang telah dibuat dan telah dicoba sebelumnya. Eksperimen ini dibagi menjadi dua tahap. Eksperimen tahap pertama adalah proses pembuatan mock up pertama, sementara eksperimen tahap kedua adalah proses pembuatan mock up kedua yang merupakan perbaikan dari mock up pertama. Pada eksperimen tahap pertama, alternatif sistem sambungan yang dibuat berjumlah enam alternatif. Sementara pada eksperimen tahap kedua, alternatif sistem sambungan yang dibuat berjumlah tiga alternatif. Alternatif sistem sambungan kedua merupakan gabungan dari beberapa sistem sambungan yang ada pada eksperimen tahap pertama. Beberapa sistem sambungan menggunakan 
sistem sliding dan sebagian menggunakan sistem rotasi. Pemilihan sistem sambungan didasarkan atas beberapa faktor yakni faktor kekuatan, keawetan dan ketahanan, kemudahan pembuatan, keringanan dimensi, kepraktisan pengaplikasian sistem kuncian, dan variasi bentuk heels yang dihasilkan.

\section{Eksperimen 1}

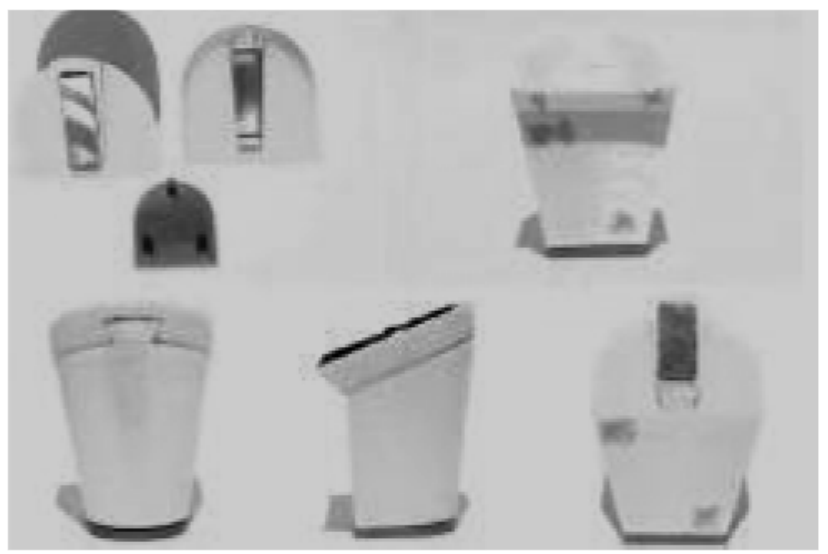

Gambar 6. Ekperimen Pertama

Menggunakan sistem sliding. Ketinggian yang dapat dihasilkan adalah hak dengan ketinggian minimal $15 \mathrm{~mm}$ (karena terdapat ulir). Bentuk yang dapat dihasilkan adalah semua jenis hak. Sistem kuncian praktis. Kekuatan dari sistem kunciannya termasuk kuat, karena sistem kuncian slide-nya menjadi penyokong dari bentukan hak. Kekurangan dari sistem ini adalah Stopper Magnet kurang kuat, dan arah sistem slide-nya terbalik

Alternatif ini gagal akibat penyambungan pir tidak sempurna dan konstruksinya kurang kokoh untuk menopang berat tubuh. Penampakan eksperimen dapat dilihat pada Gambar 6.

\section{Eksperimen 2}

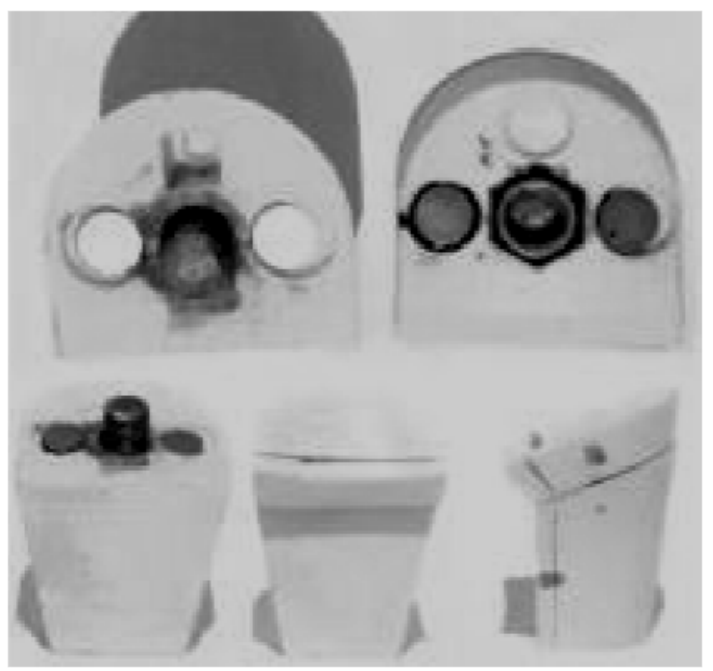

Gambar 7. Eksperimen Kedua

Menggunakan sistem ulir. Bentuk yang dapat dihasilkan adalah semua jenis hak. Kekuatan dari sistem kunciannya termasuk kuat, karena sistem kuncian slide-nya menjadi penyokong dari bentukan hak. Setelah direkatkan, dan dibuat untuk berjalan ternyata sambungannya kuat untuk menahan beban tubuh. Kekurangan dari sambungan ini adalah stopper magnetnya kurang kuat. Penampakan eksperimen dapat dilihat pada Gambar 7.

\section{Eksperimen 3}

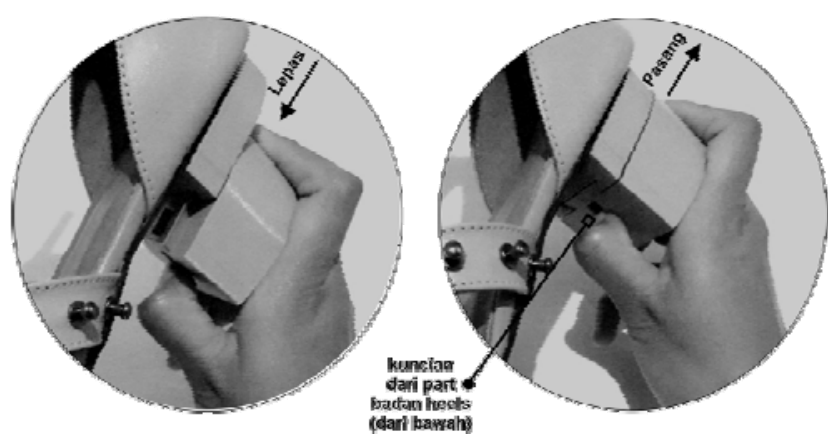

Gambar 8. Eksperimen Ketiga

Menggunakan sistem sliding. Kelebihan pada sistem ini adalah pengoperasaian yang relatif mudah dan praktis. Kekurangan pada sistem ini adalah sistemnya harus dibuat satu persatu pada bagian badan hak. Dan karena rongga stopper-nya harus berada di tempat yang sama, maka hal tersebut mempengaruhi pada bentuk hak yang dibuat, sehingga bentuk hak yang dibuat kurang dapat bervariasi. Dan ketinggian yang dapat dihasilkan adalah hak dengan ketinggian minimal $30 \mathrm{~mm}$ (karena terdapat stopper di dalam bagian badan hak). Penampakan eksperimen dapat dilihat pada Gambar 8 .

\section{Eksperimen 4}

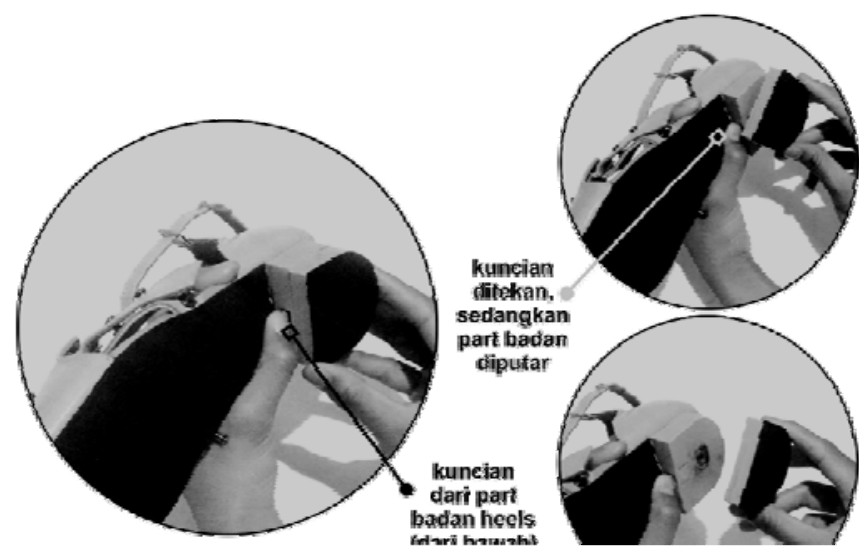

Gambar 9. Eksperimen Keempat

Menggunakan sistem ulir. Kelebihan pada sistem ini adalah pembuatan sistemnya relatif mudah. Hak yang dihasilkan dapat bervariasi, dan kekuatan dari sistem kunciannya termasuk kuat, karena sistem kuncian rotasinya menjadi penyokong dari bentukan hak. Kekurangan pada sistem ini adalah pengoperasaiannya relatif kurang praktis. pengaplikasian sistem kurang praktis (Gambar 9). Dan ketinggian yang dapat dihasilkan adalah hak dengan ketinggian minimal $25 \mathrm{~mm}$ (karena terdapat ulir di dalam).

\section{Eksperimen 5}

Menggunakan sistem sliding. Kelebihan pada sistem ini adalah pembuatan sistemnya relatif mudah, hak yang dihasilkan dapat bervariasi karena posisi stopper-nya 
terdapat di bagian atas. Dan juga dimensinya sambungan lebih ringkas, sehingga ketinggian hak yang dapat dihasilkan adalah hak dengan ketinggian minimal $15 \mathrm{~mm}$ (karena terdapat stopper di dalam). Bentuk yang dapat dihasilkan adalah semua jenis hak. Kekuatan dari sistem kunciannya termasuk kuat, karena sistem kuncian slide-nya menjadi penyokong dari bentukan hak (Gambar 10).

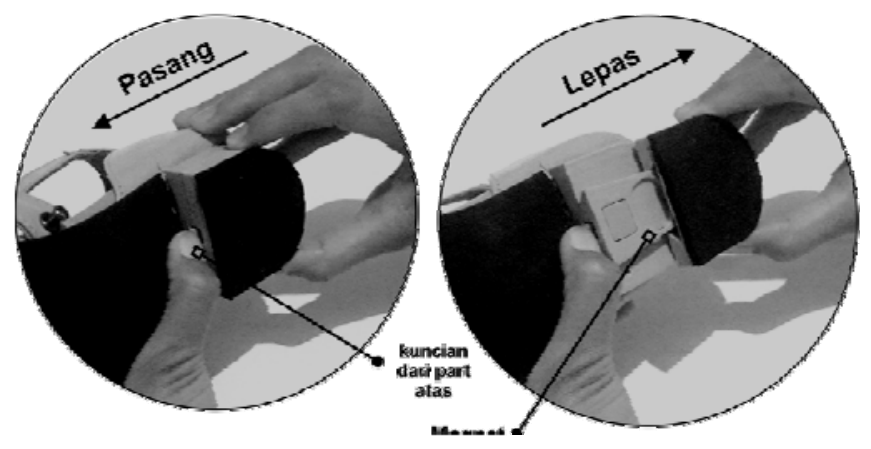

Gambar 10. Eksperimen Kelima

Dari data tersebut dapat disimpulkan bahwa sistem assembly hak yang tepat untuk diterapkan pada perancangan ini adalah sistem assembly hak kelima, berupa sistem sliding dengan kuncian tombol yang ketika pada posisi normal akan mengunci, sementara ketika tombolnya ditarik akan melepas kunciannya. Sistem ini memiliki kelebihan pada kemudahan pembuatan, dimensi yang ringan, dan bentuk heels yang dihasilkan dapat bervariasi. Tabel 2 menunjukkan perbandingan sudut kemiringan hak dibandingkan dengan hasil penelitian sebelumnya.

Berdasarkan percobaan yang telah dilakukan pada sepatu yang telah dibuat dengan panjang bantalan sepatu adalah 70 $\mathrm{mm}$, ternyata mencapai kenyamanan yang tepat pada sudutsudut kemiringan yang berbeda dengan sudut-sudut kemiringan yang dilakukan oleh peneliti-peneliti sebelumnya. Untuk hak dengan ketinggian $25 \mathrm{~mm}$ menggunakan sudut kemiringan 5 derajat, hak dengan ketinggian $50 \mathrm{~mm}$ menggunakan sudut kemiringan 15 derajat, dan hak dengan ketinggian $75 \mathrm{~mm}$ menggunakan sudut kemiringan 22 derajat.

\begin{tabular}{|c|c|c|c|}
\hline No. & $\begin{array}{l}\text { Ketinggian } \\
\text { hak / Heel } \\
\text { height }(\mathrm{H})\end{array}$ & $\begin{array}{c}\text { Panjang } \\
\text { Bantalan Tumit } \\
\text { / Heel seat } \\
\text { length (L) }\end{array}$ & $\begin{array}{c}\text { Sudut } \\
\text { Kemiringan } \\
\text { Hak/ Heel } \\
\text { Wedge } \\
\text { Angle }(\mathbf{\Theta}) \\
\end{array}$ \\
\hline \multirow{3}{*}{1} & \multirow{3}{*}{$25 \mathrm{~mm}$} & $45 \mathrm{~mm}$ & $5^{\circ}$ \\
\hline & & $67,5 \mathrm{~mm}$ & $4^{\circ}$ \\
\hline & & $70 \mathrm{~mm}$ & $10^{\circ}$ \\
\hline \multirow{3}{*}{2} & \multirow{3}{*}{$50 \mathrm{~mm}$} & $45 \mathrm{~mm}$ & $8^{\circ}$ \\
\hline & & $67,5 \mathrm{~mm}$ & $10^{\circ}$ \\
\hline & & $70 \mathrm{~mm}$ & $15^{\circ}$ \\
\hline \multirow{3}{*}{3} & \multirow{3}{*}{$75 \mathrm{~mm}$} & $45 \mathrm{~mm}$ & $18^{\circ}$ \\
\hline & & $67,5 \mathrm{~mm}$ & $8^{\circ}$ \\
\hline & & $70 \mathrm{~mm}$ & $22^{\circ}$ \\
\hline
\end{tabular}

\section{KESIMPULAN}

Pada pengembangan desain sepatu wanita dengan sistem interchangeable ini terdapat aspek yang harus diperhatikan pada pembuatannya (Gambar 12 dan 13), yaitu:

1. Kefleksiblean pada insol dan outsol sepatu juga harus diperhatikan. Hal tersebut mempengaruhi tingkat kenyamanan sepatu. Pemilihan material pada insol dan outsol merupakan kunci utama dalam faktor kefleksibilitasannya.
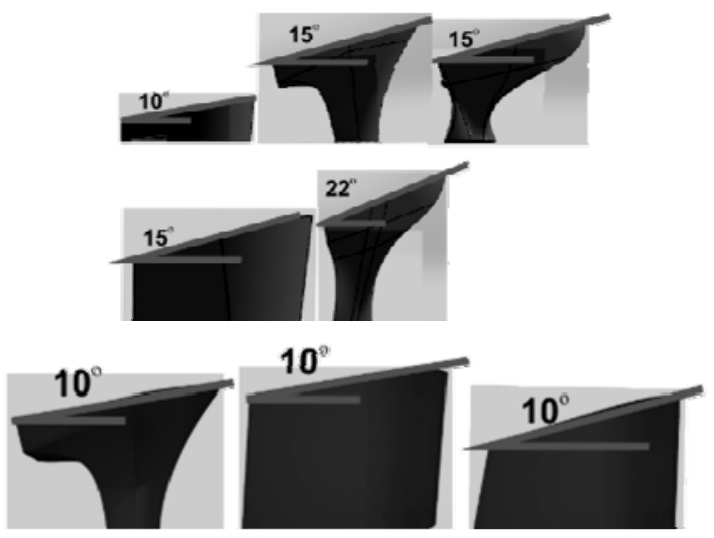

Gambar 11. (Atas) Hasil eksperimen kemiringan hak yang benar. (Bawah) Hasil eksperimen kemiringan hak yang salah.

2. Setiap ketinggian hak sepatu memiliki kemiringan sudut hak yang berbeda. Hal tersebut mempengaruhi tingkat kenyamanan sepatu. Karena untuk setiap ketiggian hak yang berbeda, angka persebaran tekanan tubuh juga berbeda. Semakin tinggi hak sepatunya, maka semakin besar tekanan tubuh pada daerah kaki depan (forefoot).
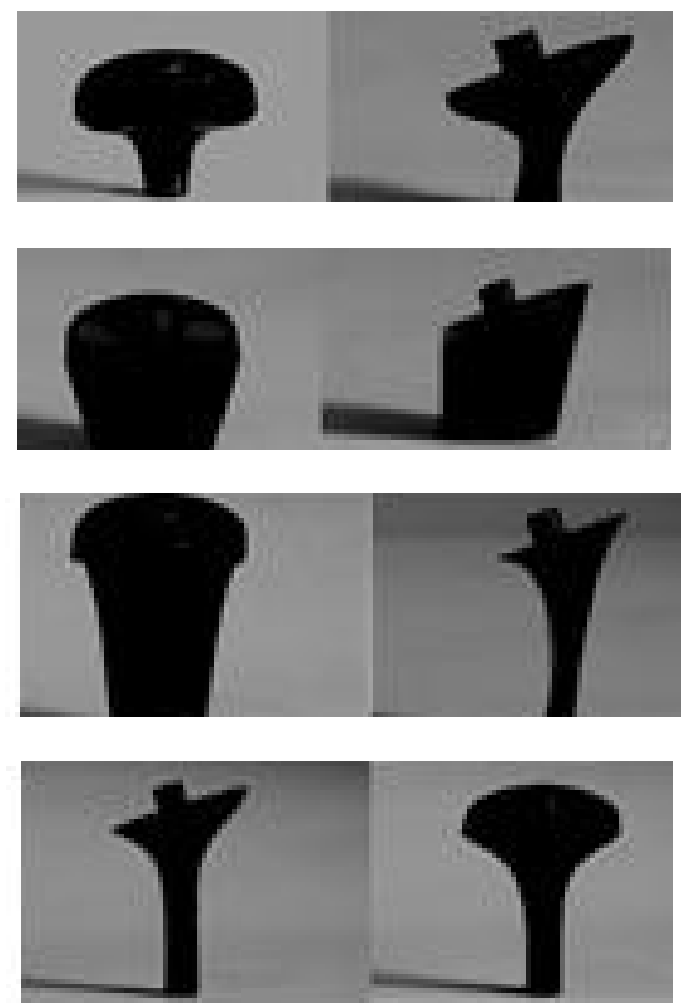

Gambar 12. Hasil eksperimen pertama hak sepatu 
3. Selain kefleksiblean pada insol dan outsol sepatu, pola upper sepatu juga harus memiliki pola yang dapat diadjustable, agar dapat menyesuaikan ketika hak sepatu dilepas-pasang.

4. Sistem sambungan hak sepatu interchangeable yang dipilih adalah sistem sliding. Setelah pada eksperimen pertama menggunakan sistem rotasi. Setelah dievaluasi kembali, ternyata sistem slidding lebih praktis dan efisien daripada sistem rotasi.
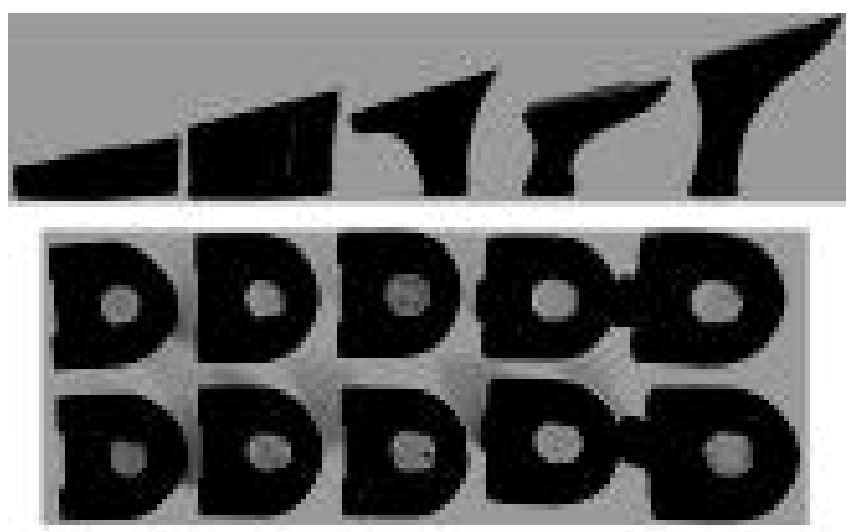

Gambar 13. Hasil eksperimen kedua hak sepatu

\section{UCAPAN TERIMA KASIH}

Penulis mengucapkan terima kasih kepada pihak-pihak yang telah membantu sehingga penelitian ini dapat diselesaikan.

\section{DAFTAR PUSTAKA}

[1] Islahuddin. (2017, September 11). Perempuan hanya mendominasi di tiga sektor pekerjaan. Retrieved Juni 1,

[2] 2018, from https://beritagar.id/artikel/berita/perempuanhanya-mendominasi-di-tiga-sektor-pekerjaan.

[3] Nurani, Lulu. (2013). Beauty In Pain kajian sosioteknis sepatu hak tinggi (high heels) pada wanita [Skripsi]. Bandung (ID): Institut Teknologi Bandung

[4] Witana, Channa P, dkk. (2009). Footbed shapes for enchanced footwear comfort. Hongkong: Hongkong University of Science and Technologi.

[5] Xiong, Shuping, Yang, Shaofei., \& Hapsari,V.D. (2014). High Heels on Human Stability and Plantar Pressure Distribution: Effects of Heel Height and Shoe Wearing Experience. Korea : Korea Advanced Institute of Science and Technology.

[6] Winata, Handy. (2010). Kaitan Pemakaian Sepatu Hak Tinggi dengan Lordosis Lumbal. Jakarta : FK UKRIDA. 